\title{
Morphology of the Normal Human Lens
}

\author{
Virginia L. Taylor,* Kristin J. Al-Ghoul,* C. Wesley Lane,* V. Andrew Davis,* \\ Jerome R. Kuszak, $\dagger$ and M. Joseph Costello*
}

\begin{abstract}
Purpose. To provide a quantitative, morphologic description of differentiated lens fiber cells in all regions of aged normal human lenses.

Methods. Transparent normal human lenses (age range, 44 to 71 years) were examined with correlative transmission electron microscopy (TEM) and scanning electron microscopy (SEM). Vibratome sections allowed examination of internal structures, whereas dissected whole lenses revealed surface characteristics. Additionally, image analysis was used to measure cross-sectional areas of fiber cells.
\end{abstract}

Results. Approximate regional dimensions (percentage of diameter and thickness, respectively) were determined for whole lenses: cortex $16 \%, 17 \%$; adult nucleus $24 \%, 21 \%$; juvenile nucleus $12 \%, 9 \%$; fetal nucleus $45 \%, 49 \%$; and embryonic nucleus $3 \%, 4 \%$. Cortical cells were irregularly hexagonal, and the average cross-sectional area measured $24 \pm 9 \mu \mathrm{m}^{2}$. Adult nuclear cells were flattened with intricate membranous interdigitations and an area of $7 \pm 2$ $\mu \mathrm{m}^{2}$. Juvenile nuclear cells had an area of $14 \pm 5 \mu \mathrm{m}^{2}$. Fetal nuclear cells were rounded with an area of $35 \pm 22 \mu \mathrm{m}^{2}$. Embryonic nuclear cells also were rounded and had a variable area of $80 \pm 68 \mu \mathrm{m}^{2}$. Fiber cell cytoplasm in all lens regions appeared smooth in texture and homogeneous in staining density.

Conclusions. Both TEM and SEM are necessary to obtain a complete description of fiber cells. Cross-sections of fibers give new insights into the lamellar organization of the lens, indicating that each region has characteristic cell shapes and sizes. Furthermore, average dimensions were used to demonstrate that the number of cells and approximate growth rates vary significantly between adjacent regions. Invest Ophthalmol Vis Sci. 1996;37:1396-1410.

The transparency of the crystalline lens has been attributed to the complex, ordered arrangement of its components at both microscopic and molecular levels. ${ }^{1}$ At the microscopic level, the regular array of flattened, hexagonal cross-sections of fiber cells epitomizes lens tissue to most researchers and clinicians. In the early literature, however, $\mathrm{Rabl}^{2}$ displayed drawings of lens fiber cells based on light microscopic observations from a variety of mammals, reptiles, and birds showing that the ordered cellular array was not present in the lens interior. More recently, Rae et $\mathrm{al}^{3}$ showed a similar packing of cells in frog lenses using

From the *Department of Cell Biology and Anatomy, University of North Carolina at Chapel Hill, and the †Departments of Pathology and Ophthalmology, RushPresbyterian-St. Luke's Medical Center, Chicago, Illinois.

Supported by National Institutes of Health grants EY08148, EY06642, and EYO5722, an Alcon Research Institute Award (JRK), and the Louise C. Norton Trust Fund.

Submitted for publication September 13, 1995; revised December 20, 1995; accepted February 9, 1996.

Proprietary interest category: $N$.

Reprint requests: $M$. Joseph Costello, Department of Cell Biology and Anatomy, University of North Carolina at Chapel Hill, CB 7090, Chapel Hill, NC 27599 7090. light microscopic examination of histologic sections. Only recently have these observations of disordered cell packing been supported at the ultrastructural level in well-preserved mammalian tissue. ${ }^{4-6}$

At the molecular level, packing of lens crystallins has been shown in the last decade to be random, with no evidence of crystalline regularity. Based on x-ray diffusion measurements in vitro, monomers, or small aggregates of crystallins, are thought to be associated closely; hence, at a critical distance, the light scattering of the concentrated protein solution decreases significantly, leading to transparency. ${ }^{7}$ Little ultrastructural information is available describing the in vivo appearance of fiber cell cytoplasm throughout aged normal human lenses. It is clear that an understanding of normal lens morphology is essential as a basis for characterizing cataract formation and age-related changes in accommodative ability.

Many electron microscopic studies have been performed on lenses, although none have demonstrated all types of lens fibers. Initial investigations were un- 


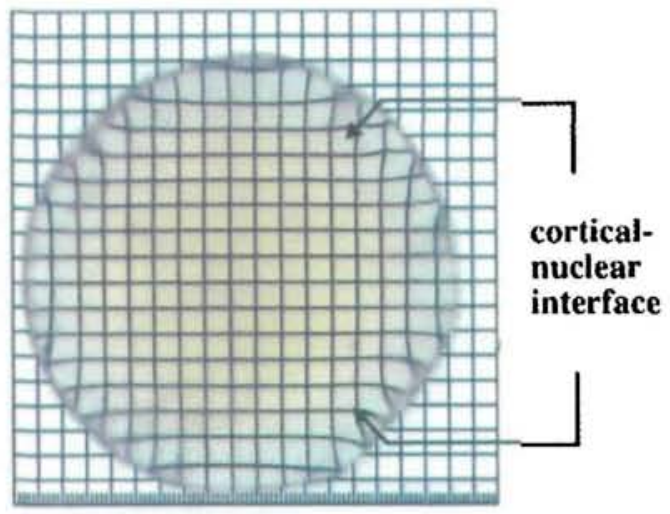

FIGURE 1. A normal human lens (age, 67 years). The cortical-nuclear interface is apparent (arrows) by the pale yellow color of the nucleus. This lens, as well as all other lenses used, was transparent throughout, as shown by the clarity of the grid lines behind the lens.

dertaken by Wanko and Gavin ${ }^{8}$ and Cohen ${ }^{9}$ on mammals and humans, respectively. Many more followed describing fibers from a variety of mammals, including rat, ${ }^{10.11}$ rabbit, ${ }^{12}$ pig, ${ }^{13}$ monkey, ${ }^{14-17}$ and human. ${ }^{15,18-23}$ Nevertheless, ultrastructural information about fiber cells throughout the lens is significantly lacking because of problems with adequate fixation, as outlined by Kuszak et al. ${ }^{23}$ Recent technical advances in fixation methods for scanning electron microscopy (SEM) ${ }^{16}$ and transmission electron microscopy (TEM) ${ }^{24}$ have made it possible to analyze differentiated fibers in all regions of the lens. However, neither SEM nor TEM alone was sufficient to provide a complete description of these fibers. Therefore, the goal of this study was to use correlative SEM and TEM to characterize lens fiber cell shape, size, cytoplasmic texture, types of interdigitations, surface morphology, and cellular organization.

The cross-sectional area of fiber cells varied from region to region, with the smallest areas found in the compressed adult nuclear region and the largest found in the central embryonic nucleus. Cellular organization was the most ordered in the cortex, where radial cell columns (RCCs) were found. Cells were more irregularly packed in the center of the lens, where no apparent arrangement was observed. The cytoplasm of intact cells was smooth and homogeneous in all regions analyzed.

\section{METHODS}

\section{Lenses}

Eight normal (noncataractous) human lenses were acquired for this study within 24 hours of death. Five whole lenses were obtained from the North Carolina Eye and Human Tissue Bank (Durham, NC), a member of the Eye Bank Association of America. For these lenses, the entire eye was enucleated within 6 hours of death and placed in a glass vial for transport. Three of the five were used for SEM examination (ages 44, 57 , and 71 years), and two were used for TEM (ages 59 and 67 years). Two whole lenses were obtained from the National Disease Research Interchange (ages 58 and 69 years) and were used for SEM. The eighth lens (age 62 years), used for TEM, was surgically extracted at Duke Medical Center (Durham, NC) from a patient who received trauma to the eye. This nucleus was wrapped in gauze soaked with a balanced salt solution and transported in a glass vial. This study followed the tenets of the Declaration of Helsinki. On examination, all eight lenses were transparent throughout and had pale yellow nuclei (Fig. 1).

\section{Lens Regions}

To determine approximate nuclear boundaries, whole normal lenses were scanned (see Image Analysis below), and the resultant images were analyzed (Fig. 1). Whole lenses also were measured with vernier calipers to determine diameter and thickness; the average equatorial diameter was $9.6 \mathrm{~mm}$, and the average anterior-to-posterior thickness was $4.2 \mathrm{~mm}$. Splitting patterns, as well as suture lines, were apparent in fresh vibratome sections; these sections were placed on glass slides and scanned into the computer (Fig. 2). Fixed sections were analyzed optically if layer separations were visible. Scanning electron microscopic pictures showed suture and splitting patterns that revealed dimensions of the nuclear core. It was shown recently that the distinct generations of vertebrate lens sutures coincide with the zones of discontinuity and lens regions. ${ }^{25}$ Therefore, suture patterns in the vibratome sections and the SEM pictures were used to identify nuclear boundaries. Values in the literature $e^{18.20 .26,27}$ were also used as guidelines, as well as for confirming

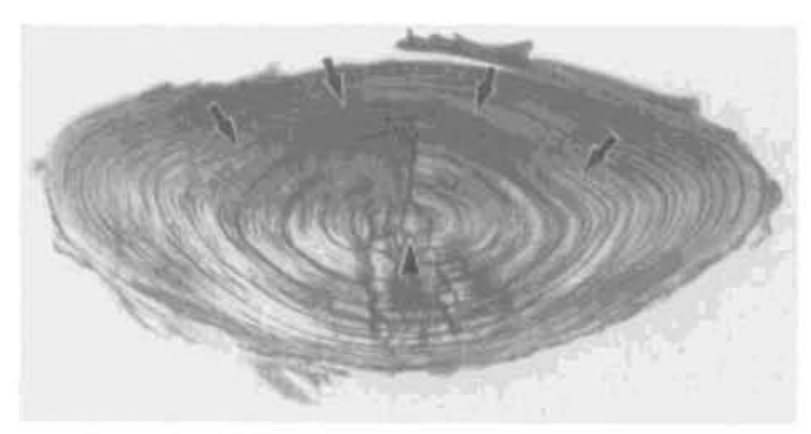

FIGURE 2. A vibratome section of a human lens. Lens fibers often separate at prominent interfaces because of vibrations during the vibratome sectioning process. In this example, the embryonic nucleus is visible in the center of the section (arrowhead), and the interface between the fetal and juvenile nuclear regions (arrows) is identified by the termination of a branch of the Y suture (vertical line above the embryonic nucleus). 
our experimental data. Finally, each region was examined by TEM to confirm a change in cell type across determined nuclear interfaces.

Fiber cells were analyzed in five regions of the lens: deep cortex (differentiated nonnuclear fiber cells), adult nucleus (differentiated fiber cells formed since puberty), juvenile nucleus (fiber cells formed from birth until the onset of puberty), fetal nucleus (fiber cells formed from the 7th week of development until birth), and embryonic nucleus (primary fiber cells formed in the 6 weeks after fertilization) ${ }^{26.28} \mathrm{Su}$ perficial cortical cells (elongating fibers) were not included in this study because of the ample morphologic data already available in the literature. ${ }^{15,18,21,23}$

\section{Transmission Electron Microscopy}

All three lenses were processed within 24 hours of death or surgery. The capsule was removed in preparation for the vibratome sectioning process previously described by $\mathrm{Al}-$ Ghoul and Costello. ${ }^{29}$ Briefly, lenses were mounted on the vibratome tray with cyanoacrylate glue and were covered with $2.5 \%$ warm agar that solidified on reaching room temperature. Vibratome sections 100 to $200 \mu \mathrm{m}$ thick were cut at a knife angle of $12^{\circ}$. Lenses were oriented so that sections were cut parallel to the optic axis. In this manner, the section that contained the optic axis also contained cells from all regions of the lens. Most sections were placed in modified Karnovsky's fixative (2.5\% glutaraldehyde, $2 \%$ paraformaldehyde, $1 \%$ tannic acid in cacodylate buffer, $\mathrm{pH}$ 7.2) for 12 to 18 hours at room temperature, although some were examined on glass slides without fixation. Sections were postfixed with $0.5 \%$ $\mathrm{OsO}_{4}$ and processed for electron microscopy as previously described. ${ }^{24}$ During the final processing step, the lens sections were embedded in an epoxy resin. For each lens, the plastic-encased section containing the optic axis was bisected to expose the equatorial plane. Mesas were raised along the exposed surface in each fiber cell region of the lens. Thin sections were cut at $60 \mathrm{~nm}$ with a diamond knife (Diatome, Fort Washington, PA) and stained with uranyl acetate and lead citrate for viewing on a JEOL 200CX transmission electron microscope (JEOL, Peabody, MD) at $80 \mathrm{kV}$. Low-magnification pictures $(\times 100$ to $\times 400)$ were taken of each region to locate areas free of dis- ruption caused by vibratome sectioning. Higher magnification pictures $(\times 2900)$ were then taken of representative areas. The accuracy of recorded magnifications was confirmed using a grating replica.

\section{Scanning Electron Microscopy}

Lenses initially were preserved in $10 \%$ neutral buffered formalin prepared in $0.1 \mathrm{M}$ phosphate buffer for 24 hours, as described previously. ${ }^{30}$ After the primary fixative was washed out, the lenses were immersed in secondary fixative $(2.5 \%$ glutaraldehyde prepared in $0.12 \mathrm{M}$ cacodylate buffer, $\mathrm{pH}$ 7.2) for 5 days, with fresh fixative added every 24 hours. Before dissection, the secondary fixative was removed by washing with $0.2 \mathrm{M}$ cacodylate for 24 hours. Each lens initially was measured, and then a cylindrical antero-posterior core was removed with a microtrephine $6 \mathrm{~mm}$ in diameter. Lens pieces were osmicated ( 24 hours in $1 \%$ aqueous osmium tetroxide at $4^{\circ} \mathrm{C}$ ), dehydrated, and critical point dried (Balzers $020 \mathrm{CPD}$ at $45^{\circ} \mathrm{C}$ and $1200 \mathrm{psi}$ ) in preparation for SEM viewing. Pieces were then mounted on aluminum stubs with silver paste and were sputter coated with gold. Samples were examined on a JEOL JSM 35c scanning electron microscope at $15 \mathrm{kV}$.

\section{Image Analysis}

The TEM negatives $\left(3 \frac{1}{2} \times 4\right.$ inches $)$ at $\times 2900$, as well as the whole lenses, were scanned at $2048 \times 2048$ pixel resolution using an Eikonix 1412 scanning CCD camera (Giesecke \& Devrient Engineering, Bedford, MA) and a DC high-intensity light source (Gordon Instruments, Orchard Park, NY). Adobe Photoshop v. 2.5 (Adobe Systems, Mountain View, CA) was used to operate the scanner on a Macintosh (Apple, Cupertino, CA) Centris 650 computer. A reticle (model no. 7; Ted Pella, Redding, CA) was scanned with each image for use as a calibration device. Images were processed using NIH Image v.1.53. ${ }^{31}$ Morphometry to determine area and perimeter was performed on a high-resolution monitor. The number of intracellular and extracellular profiles also was determined for each cell studied. The majority of intracellular profiles were "balls" of ball-and-socket junctions that were cut in cross-section and project into neighboring cells. In contrast, an extracellular profile is a cross-sectional

FIGURE 3. Comparison of normal human lens fiber cells from five different regions: (A) deep cortex, (B) adult nucleus, (C) juvenile nucleus, (D) fetal nucleus, (E) embryonic nucleus. The variation in fiber cell area between regions is obvious. Structural characteristics observed include: ball-and-socket interdigitations (open arrows), intracellular profiles (arrows), extracellular profiles (curved arrows), high-amplitude undulating membranes (arrowheads), and lowamplitude undulating membranes (wavy lines). The radial cell column is evident in $\mathbf{A}$ and is outlined in $\mathbf{B}$ and $\mathbf{C}$. Note that the staining density of the cytoplasm is uniform in all regions shown. 

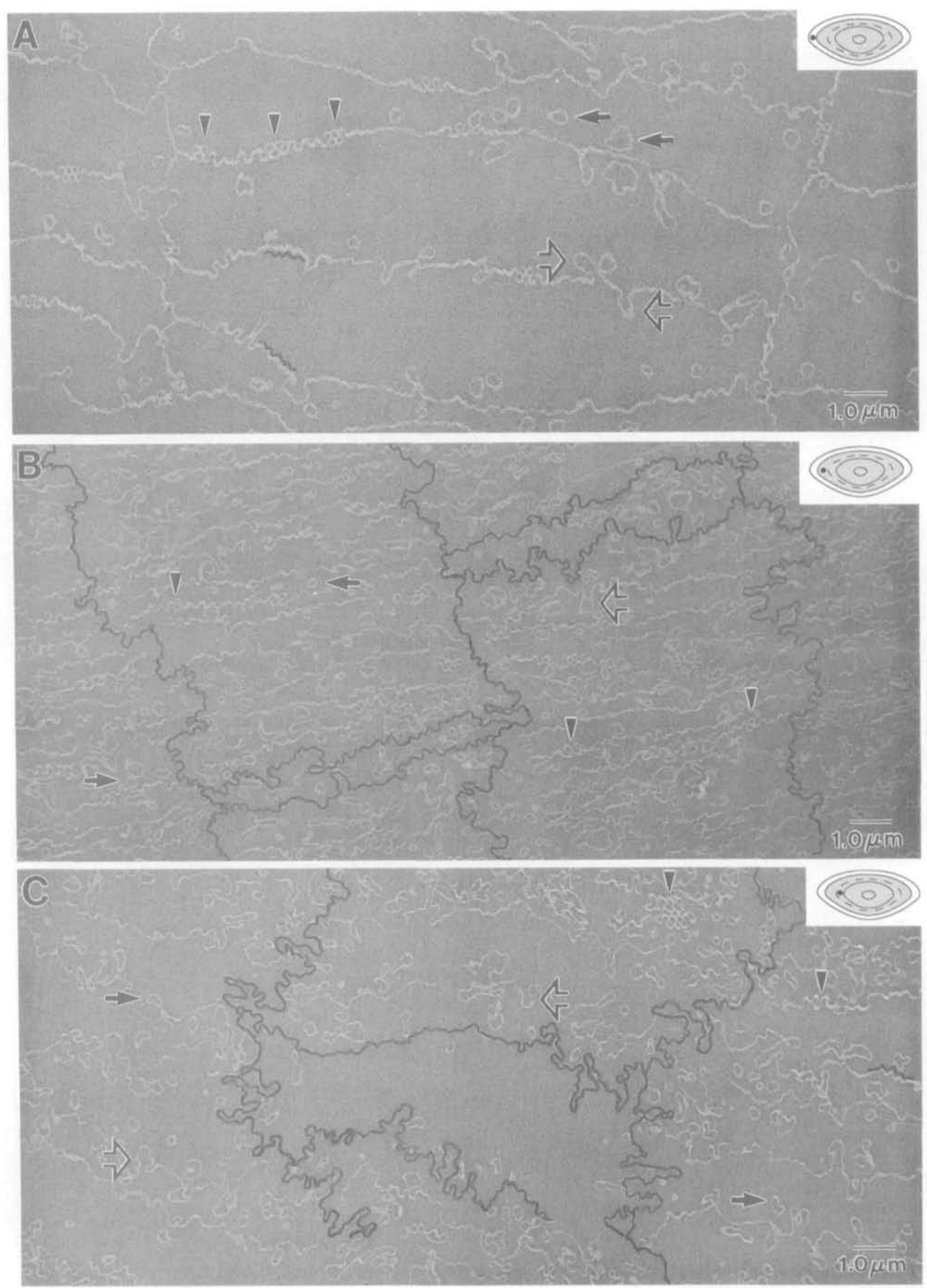

FIGURE 3. 

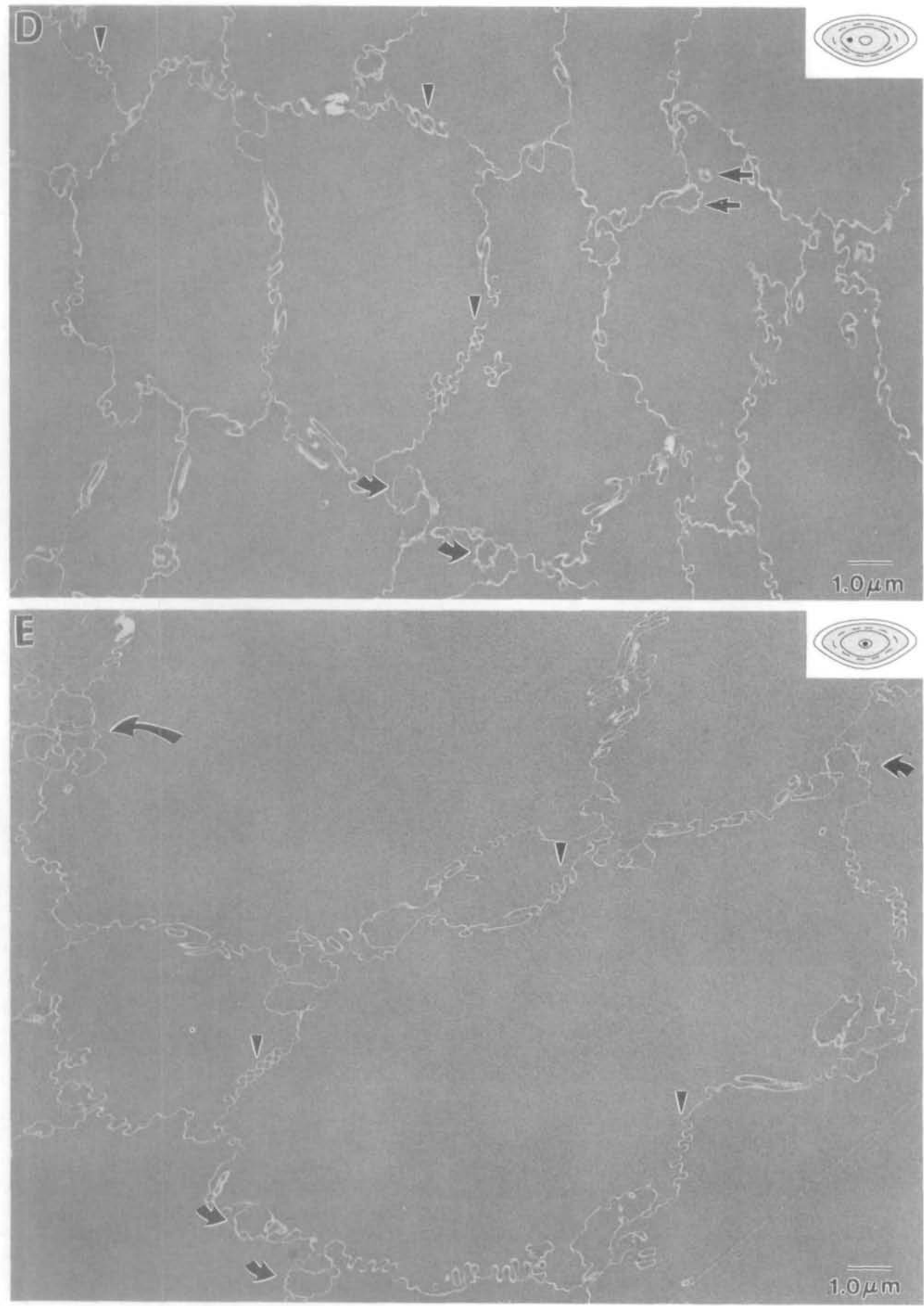

FIGURE 3. (Continued) 
view of an interlocking edge process (see Discussion). All cells with an intact perimeter were analyzed to ensure random selection. Approximately 70 cells were examined in each region.

\section{Statistical Analysis}

Using Microsoft Excel (Microsoft, Redmond, WA), the data were graphed and found to have a nonnormal distribution. Therefore, a nonparametric test, the Wilcoxon ranked sum test, was used to determine whether area means for each region were significantly different. $^{32}$

\section{RESULTS}

\section{Fiber Cell Morphology in Transmission Electron Microscopic Images}

Fiber cell cross-sections observed in the deep cortex along the equatorial axis exemplified material presented previously for normal human lenses. ${ }^{15,18} \mathrm{~A}$ distorted hexagonal shape was apparent, and no membranous organelles were present (Fig. 3A). The average cross-sectional area of these cells was $24 \pm 9 \mu \mathrm{m}^{2}$ (area \pm SD; refer to Table 1 for a complete summary of quantitative results). Deep cortical cells were similar in size, as supported by the small standard deviation, and displayed distinct RCCs as shown in Figure 3A. The cell membranes exhibited classical ball-andsocket interdigitations (Fig. 3A, open arrows) common to the cortex ${ }^{33-35}$ Areas of high amplitude (Fig. 3A, arrowheads) and low amplitude (Fig. 3A, wavy lines) undulating membrane pairs were present. ${ }^{4}$ In the literature, these high-amplitude undulating membranes have also been described as tongue-and-groove interdigitations, ${ }^{33}$ furrowed membranes, ${ }^{16}$ microplicae, ${ }^{13,17,19}$ and grooves and ridges. ${ }^{35}$ Circular membrane profiles were present inside the cell (Fig. 3A, arrows), whereas few extracellular profiles were seen.

Adult nuclear cells appeared flattened and more irregular than the deep cortical cells (Fig. 3B). Their area was $7 \pm 2 \mu \mathrm{m}^{2}$, confirming that they had undergone compaction. In spite of their irregular shapes, the adult cells were consistent in area as indicated by the small standard deviation. Cellular packing in RCCs was discernible only after tracing the cell borders (Fig. 3B, outlines). Many intracellular profiles were seen (Fig. 3B, arrows), whereas extracellular profiles rarely were present. The membranes of adult cells were folded extensively, and complex interdigitations were common. Ball-and-socket interdigitations (Fig. 3B, open arrows) and high-amplitude undulating membranes (Fig. 3B, arrowheads) were present.

The cells of the juvenile nucleus were similar in shape to those of the adult nucleus (Fig. 3C). However, their area was twice as large $\left(14 \pm 5 \mu \mathrm{m}^{2}\right)$, and thicker cells often were interspersed among thinner cells (Fig. 3C). This slight variation in cell size corresponded to the slight increase in standard deviation. Cells were organized in indistinct RCCs (Fig. 3C, outlines). Again, intracellular profiles (Fig. 3C, arrows) were more prevalent than extracellular profiles. The cell membranes exhibited the same structures previously described: high-amplitude undulating membranes (Fig. 3C, arrowheads), low-amplitude undulating membranes (Fig. 3C, wavy line), and ball-andsocket interdigitations (Fig. 3C, open arrows).

Fiber cell shape and area were significantly different within the fetal nucleus (Fig. 3D) compared to the outer three lens regions. In cross section the cells were rounded and polygonal with a measured area of $35 \pm 22 \mu \mathrm{m}^{2}$. Fetal cells were organized in irregular rows, and some variation in area occurred, made evident by the high standard deviation. Intracellular profiles (Fig. 3D, arrows) and extracellular profiles (Fig. $3 \mathrm{D}$, curved arrows) were seen in equal proportion. It was observed that the extracellular profiles were predominantly found at the "corners" of the polygonal cells. In contrast, high-amplitude undulations were present on the "flat" sides of the cells, which interconnected the corners (Fig. 3D, arrowheads).

Embryonic nuclear cells were irregularly polygonal and had areas of $80 \pm 68 \mu \mathrm{m}^{2}$. As indicated by the standard deviation, the area varied greatly. Both large and small cells were present, arranged in no evident pattern (Fig. 3E). Extracellular profiles were prevalent (Fig. 3E, curved arrows), often clustered in groups (Fig. 3E, long curved arrow), whereas few intracellular profiles were observed. Areas of high-amplitude undulating membranes (Fig. 3E, arrowheads) were common. For all regions studied with TEM, cytoplasm of intact fiber cells was smooth and homogeneous, and there was no indication of heterogenous protein density.

\section{Fiber Cell Morphology in Scanning Electron Microscopic Images}

Dissection methods used to study fiber cells of the deep cortex, adult nucleus, and juvenile nucleus with SEM involved "peeling away" layers of fibers, thereby revealing the broad surfaces of the cells. Characteristics of these broad surfaces were similar for all three regions. Ball-like projections (Figs. $4 \mathrm{~A}$ to $4 \mathrm{C}$, open arrows) and their complementary sockets (Figs. 4A to $4 \mathrm{C}$, arrows) were numerous. Random domains of furrowed membranes, corresponding to the undulating membranes observed with TEM, were prominent on cells of the adult and juvenile nuclei and less pronounced on cortical cells (Figs. 4A to 4C, arrowheads). The surface texture of the adult and juvenile fiber cells was rough compared to that of the deep cortex; this observation is consistent with the irregular cell borders seen with TEM (Figs. 3B, 3C). Except for the sutural regions (data not shown), images of all three 
TABLE 1. Quantitative Data* From Analysis of Differentiated Fiber Cells

\begin{tabular}{lccccc}
\hline & $N$ & Average Area $\pm S \boldsymbol{S}\left(\boldsymbol{\mu \boldsymbol { m } ^ { 2 } )}\right.$ & Range $\left(\boldsymbol{\mu m ^ { 2 } )}\right.$ & Average IP & Average EP \\
\hline Cortex & 77 & $24 \pm 9$ & $12-56$ & 7 & 0.1 \\
Adult nucleus & 78 & $7 \pm 2$ & $3-18$ & 8 & 0.5 \\
Juvenile nucleus & 56 & $14 \pm 5$ & $6-28$ & 13 & 0.5 \\
Fetal nucleus & 89 & $35 \pm 22$ & $7-122$ & 2 & 3 \\
Embryonic nucleus & 65 & $80 \pm 68$ & $7-308$ & 3 & 9 \\
\hline
\end{tabular}

$\mathrm{N}=$ number of cells analyzed; IP = intracellular profiles per cell; $\mathbf{E P}=$ extracellular profiles per cell.

* Data were combined for all three lenses because there was small interlens variation.

outer lens regions show no apparent variation in cell width along the length of the fibers.

The lens inner core containing the fetal and embryonic regions was bisected along the optic axis to reveal the surfaces of these cells (Figs. 4D to $4 \mathrm{H}$ ). As described in the previous section, fetal and embryonic cells are polygonal with many flat sides rather than two distinct broad sides. Longitudinal SEM images of these inner lens core cells often display one or two of these flat sides of a particular cell at one time. Therefore, these images can appear to be similar to images of the outer three lens regions. With TEM the true differences in area can be made apparent. In the fetal nucleus, cell surfaces were covered by a complex arrangement of furrowed membranes (Fig. 4D, arrowheads) and ball-and-socket interdigitations (Fig. 4D, open arrows). Complex globular structures were observed projecting from the edges of cells (Fig. 4D, curved arrows). These have been termed edge protrusions, ${ }^{35}$ irregular lateral interdigitations, ${ }^{23}$ irregular socket junctions, ${ }^{15}$ edge processes ${ }^{19}$ and ball-andsocket junctions. ${ }^{14}$ With TEM, these globular structures appear as profiles in the extracellular space (Figs. 3D, 3E, curved arrows), a feature that distinguishes them from other types of interdigitations. For the sake of clarity, we propose the descriptive term, "interlocking edge processes."

The oldest cells of the embryonic nucleus had surface characteristics similar to those of the fetal nucleus. Furrowed membranes were prominent, covering the surfaces of the fibers (Fig. $4 \mathrm{H}$, arrowheads). Ball-and-socket interdigitations, however, were absent. Interlocking edge processes were numerous and formed clusters in some areas (Fig. $4 \mathrm{H}$, curved arrows). In fetal and embryonic regions, a distinct ac- cordion-like wrinkling was observed along the long axis of fiber cells (Figs. 4D, 4G, 4H).

\section{Lens Regions}

The approximate diameter and thickness, respectively, was determined for each lens region and expressed as a percentage of the whole: cortex $16 \%$, $17 \%$; adult nucleus $24 \%, 21 \%$; juvenile nucleus $12 \%$, $9 \%$; fetal nucleus $45 \%, 49 \%$; and embryonic nucleus $3 \%, 4 \%$. These values are shown in diagrammatic form in Figure 5, based on an average lens diameter of 9.6 $\mathrm{mm}$, an average lens thickness of $4.2 \mathrm{~mm}$, and an average age of 61 years.

\section{Statistical Analysis}

Area means (Table 1) for all five lens regions were found to be significantly different with $95 \%$ confidence. Values for each rank sum test were $P<0.001$, except for the comparison between the cortical area and the fetal area, which was $P<0.01$.

\section{DISCUSSION}

\section{Cellular Morphology}

Although morphologic studies of the normal human lens have been performed previously, this is the first to describe the structure of differentiated fiber cells from all nuclear regions. The nomenclature of the regions described in this study is based on development (see introduction); however, these designations are also consistent with many features of the lens. For example, slit lamp analysis of lenses reveals a layered structure with zones of discontinuity that divide the regions roughly into the layers we have de-

FIGURE 4. Surface characteristics of normal human lens fiber cells from five different regions: (A) deep cortex, (B) adult nucleus, (C) juvenile nucleus, (D) fetal nucleus, (F to $\mathbf{H}$ ) embryonic nucleus. The nuclear core (fetal and embryonic nuclei) is shown in (E). Balls (open arrows) and sockets (arrows) were present on younger cells, whereas complex interlocking edge processes (curved arrows) were prevalent on older cells. All broad surfaces were covered by furrowed membranes that became more numerous and complex with age (arrowheads). 

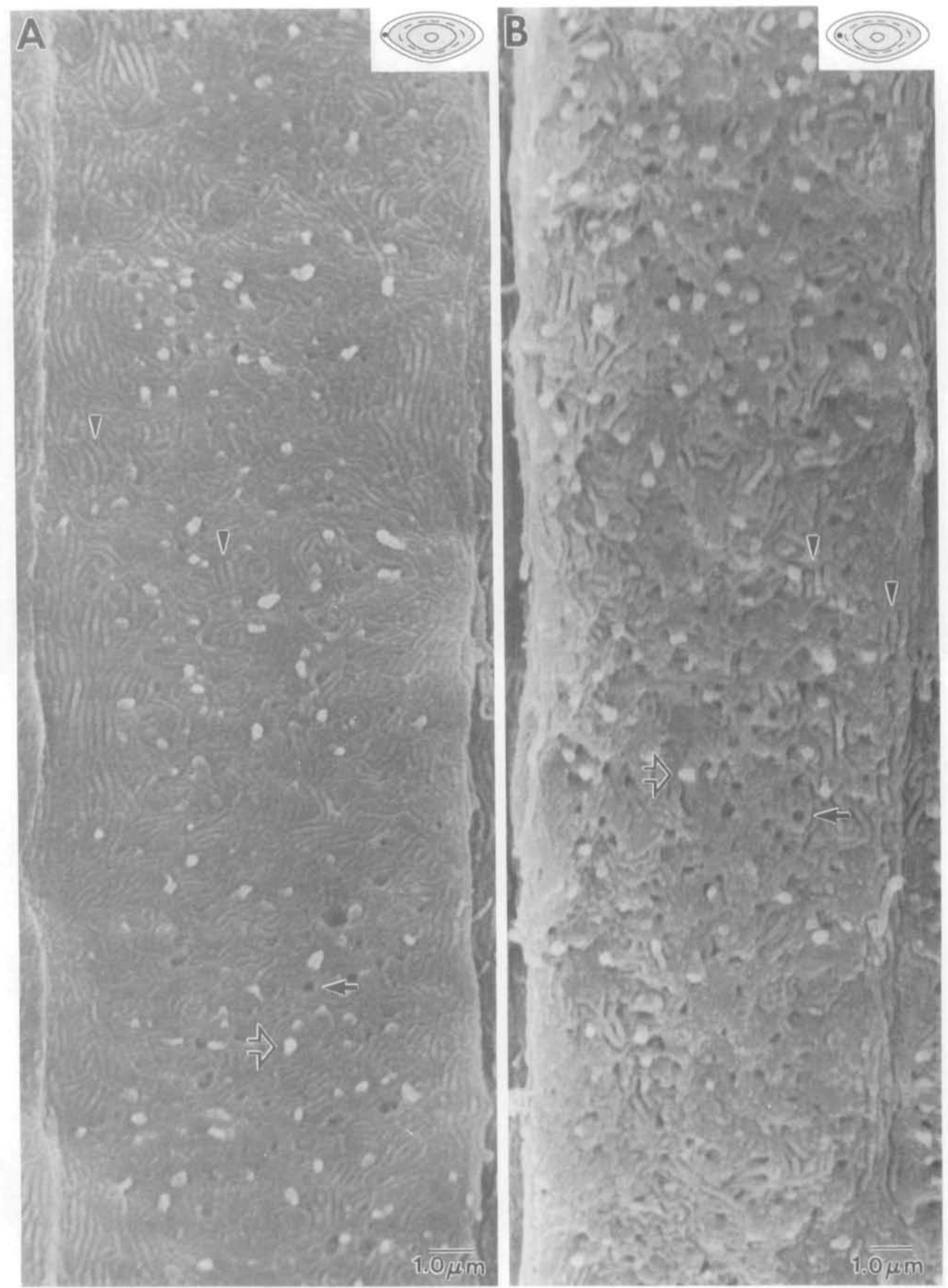

FIGURE 4. 

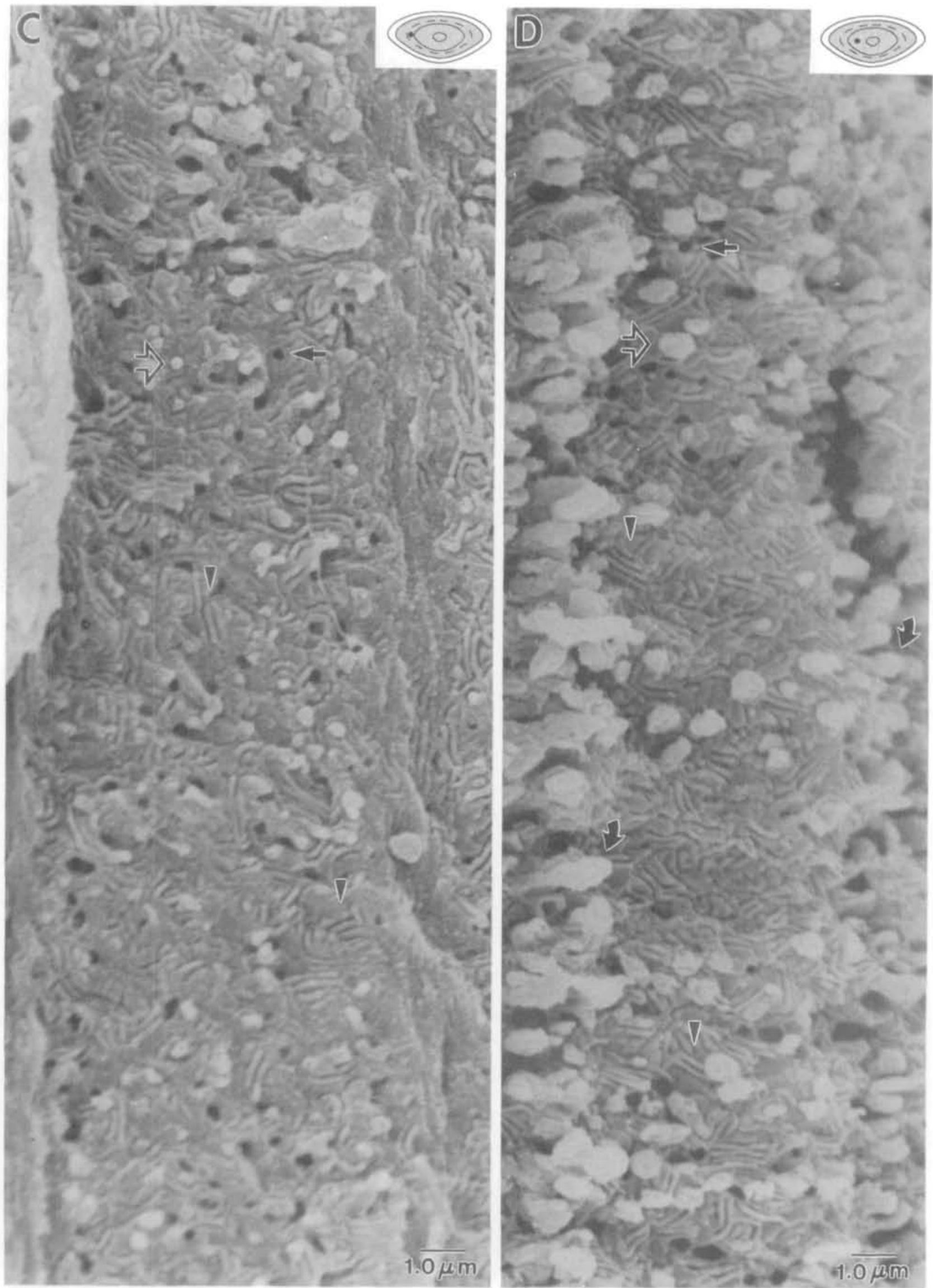

FIGURE 4. (Continued) 

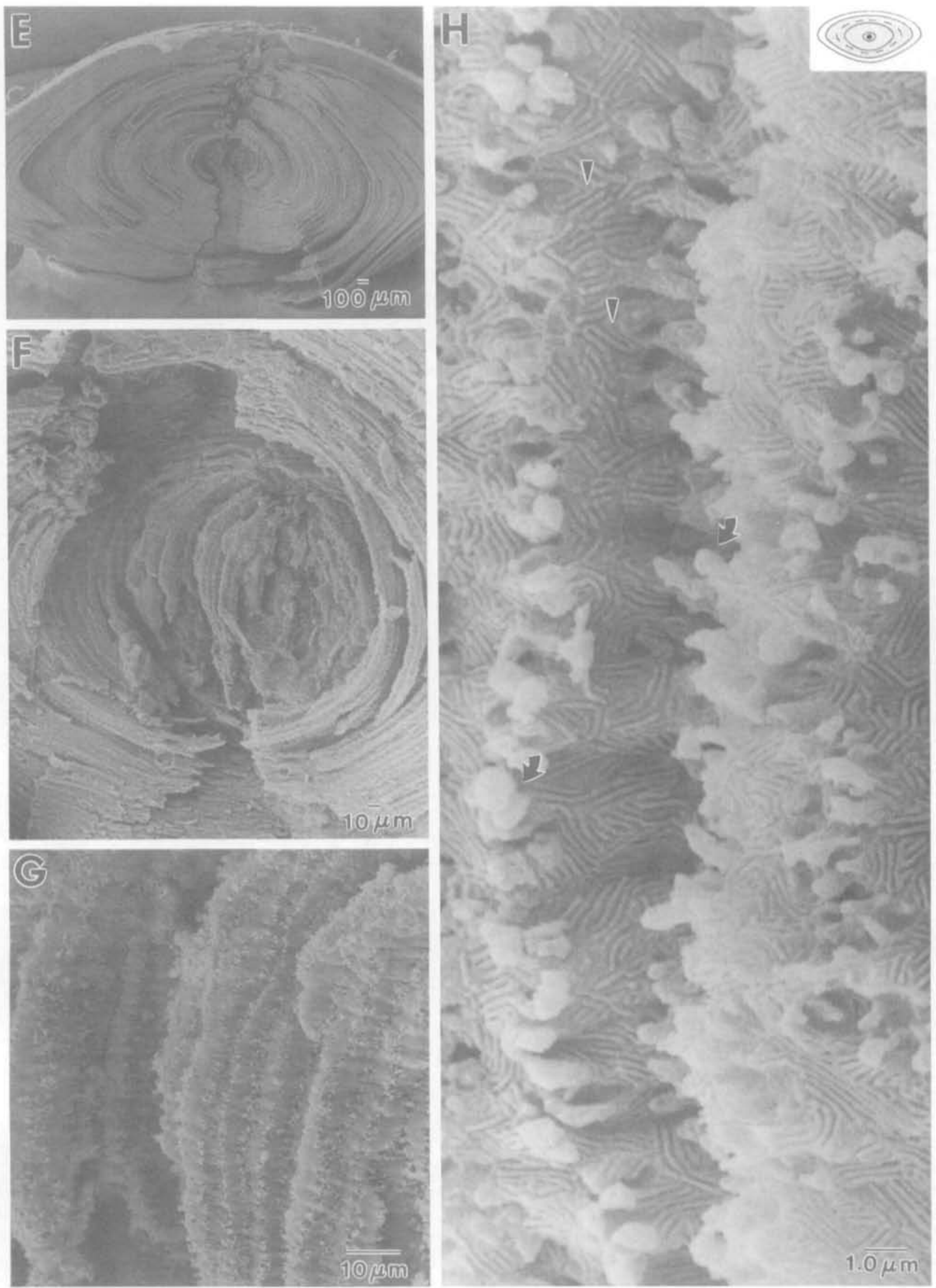

FIGURE 4. (Continued) 
scribed. ${ }^{26.27 .36}$ The four distinct generations of vertebrate lens sutures that form during lens development have been shown to correspond to these layers. ${ }^{25}$ Moreover, the texture of older lenses during dissection or surgical extraction indicates similar regions. The hardened nuclear core corresponds to the fetal and embryonic nuclei, the outer soft layer corresponds to the cortex, and the layer between, with intermediate hardness, corresponds to the adult and juvenile nuclei. Recently, the term "epinucleus" has been used to describe this intermediate layer of tissue corresponding to the adult plus juvenile nuclei. ${ }^{37}$ Biochemically, a correlation was observed between the protein modifications of lens crystallins and the lens regions. ${ }^{38}$ Nevertheless, the primary justification for distinguishing these regions is the distinct ultrastructural appearance of the fiber cells observed in each location. We think the terms used here will provide a foundation for relating research and clinical observations about lens aging and cataract formation.

The morphologic observations are summarized diagrammatically in Figure 6 . All cross-sectional views were obtained along the equatorial plane, which is depicted as a "shelf" in Figure 6. The appearance of deep cortical cells was consistent with images published previously. ${ }^{1,16,19,39}$ These cells have a constant area and are arranged in ordered radial cell columns.

In the adult nucleus, the average area of fiber cells was less than that of the deep cortex by more than a factor of three (Table 1). These data indicate that the deep cortical fibers were compacted as they were internalized and became part of the adult fiber mass. Changes in shape occurred in the absence of significant membrane loss or turnover, which resulted in an increase of membranous undulations. The small variation in size of the adult nuclear fibers implies that cells were affected equally by this compaction. Both mechanical compression, caused by the continual deposition of new fibers, and dehydration, regulated by the osmotic properties of the crystallins, are involved in this process of compaction. ${ }^{40-42}$

Cells in the juvenile nucleus were, on average, twice the size of adult cells and approximately half the size of deep cortical cells (Table 1). This suggests that juvenile cells also were compacted, but not to the degree that the adult cells were. Different developmental events or protein modifications may occur during the formation of juvenile cells, in contrast to adult cells, because they are formed before puberty. The crystallins of the juvenile cells may resist compaction because initially they may be more dehydrated than those of the adult cells. Alternatively, some cells may form in a larger state, or cells may fuse together during elongation ${ }^{30,43}$; both these events would produce cells with larger areas. Radial cell columns could be detected in adult and juvenile regions but were difficult to visualize because of the intricate folding of the membranes.
Together, the adult and juvenile nuclei comprise an annular ring that undergoes significant compaction with age and, importantly, is flanked by regions that are compacted relatively less with age. These longterm changes in radial cell thickness place constraints on cell shape, size, and packing. Possible cell-to-cell fusion also influences packing, especially near the poles and at the sutures. The simplest explanation for the observed changes in this annular ring is that the cytoskeleton is lost in the last stages of cortical differentiation and that the nuclear fibers are squeezed under pressure against a harder nuclear core (fetal and embryonic nuclei), resulting in gradual dehydration of crystallins and cellular compaction. Alternatively, self-association of the crystallins and the resultant decrease in osmotic pressure may induce dehydration of the cytoplasm. ${ }^{42}$

Within the fetal nucleus, cellular features, including shape, size, and arrangement, indicated that secondary cells formed before birth were significantly larger and more disordered than cells formed after birth (Table 1). Radial cell columns were never very pronounced in this region; instead short, irregular rows of cells were observed. With SEM, interlocking edge processes were seen on the edges of fetal cells (Fig. 4D, curved arrows) and were similar in appearance to ball-and-socket interdigitations. Transmission electron microscopic images, however, revealed the difference between these two types of interdigitations. The ball of a ball-and-socket interdigitation projects from one cell to another; when cut in cross-section, it is seen as an intracellular profile (Fig 3D, arrows). Interlocking edge processes, however, project tightly between cells, producing an extracellular profile when viewed by TEM (Fig. 3D, curved arrows). Therefore, we believe that interlocking edge processes are unique; they are characterized by irregular, globular processes projecting from the polygonal edges of cells into the extracellular space. It should be noted that these processes do not widen the extracellular space because they are tightly wedged between cells. Rather, as has been suggested for other interlocking devices, ${ }^{14,35}$ these intricate interdigitations most likely hold fibers in close apposition to prevent enlargement of the extracellular space.

Using SEM, it was apparent that fetal and embryonic cells were compressed slightly along their length in an accordion-like fashion (Figs. 4D, 4G, 4H). The resultant slight variation in cell diameter from this wrinkling may account in part for the variability in average cell area measured from thin sections cut perpendicularly to the fiber axes. This could not completely account for the large range of sizes, however (Table 1). It is likely that the fiber cells formed before birth have different developmental influences that induce variability in cell area.

The approximate sizes of the nuclear regions also 


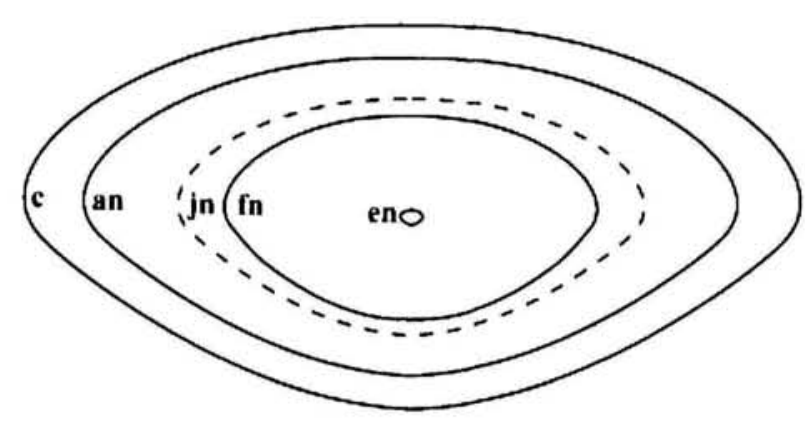

FIGURE 5. Approximate diameter and thickness of the fiber cell regions of the lens (drawn to scale based on a lens equatorial diameter of $9.6 \mathrm{~mm}$ ). $\mathrm{c}=$ cortex; an $=$ adult nucleus; $\mathrm{jn}=$ juvenile nucleus; $\mathrm{fn}=$ fetal nucleus; $\mathrm{en}=$ embryonic nucleus.

provide insight into possible differences in function (Figs. 5, 6). Nuclear cells produced during a six-decade period after birth were compacted to approximately the same fraction of the lens optic path as nuclear cells produced in the nine months before birth. This observation suggests that the outer nuclear regions (adult and juvenile nuclei) may have some functions distinct from those of the inner nuclear regions (fetal and embryonic nuclei). For example, the outer regions may function in part to maintain the flattened shape of the whole lens, thus preventing a dramatic change in lens size as new cells are added. Moreover, based on cell area measurements (Table $1)$, the pronounced compaction of the cell cytoplasm that occurs at the cortical-nuclear interface is not matched by equivalent compaction of the fetal and embryonic cells. Therefore, the primary and early secondary fiber cells, in addition to being larger than secondary fiber cells produced after birth, are stable and relatively unchanged in shape. This stability against age-related compaction may be related to the crystallin composition-specifically, higher concentrations of certain gamma-crystallins produced in early development may promote greater initial protein concentrations (less initial water) and consequently less dehydration during aging. . $^{41,42,44-46}$ Thus, the fetal and embryonic nuclei may form the primary optical element, providing the greatest focusing power, minimizing spherical aberration caused by the high refractive index, and resisting significant structural modification throughout the lives of most humans.

High-amplitude undulating membranes were seen on the surfaces of all nuclear fiber cells with both TEM (Fig. 3, arrowheads) and SEM (Fig. 4, arrowheads) and were more numerous, intricate, and distinct on older cells. This correlation between the com-

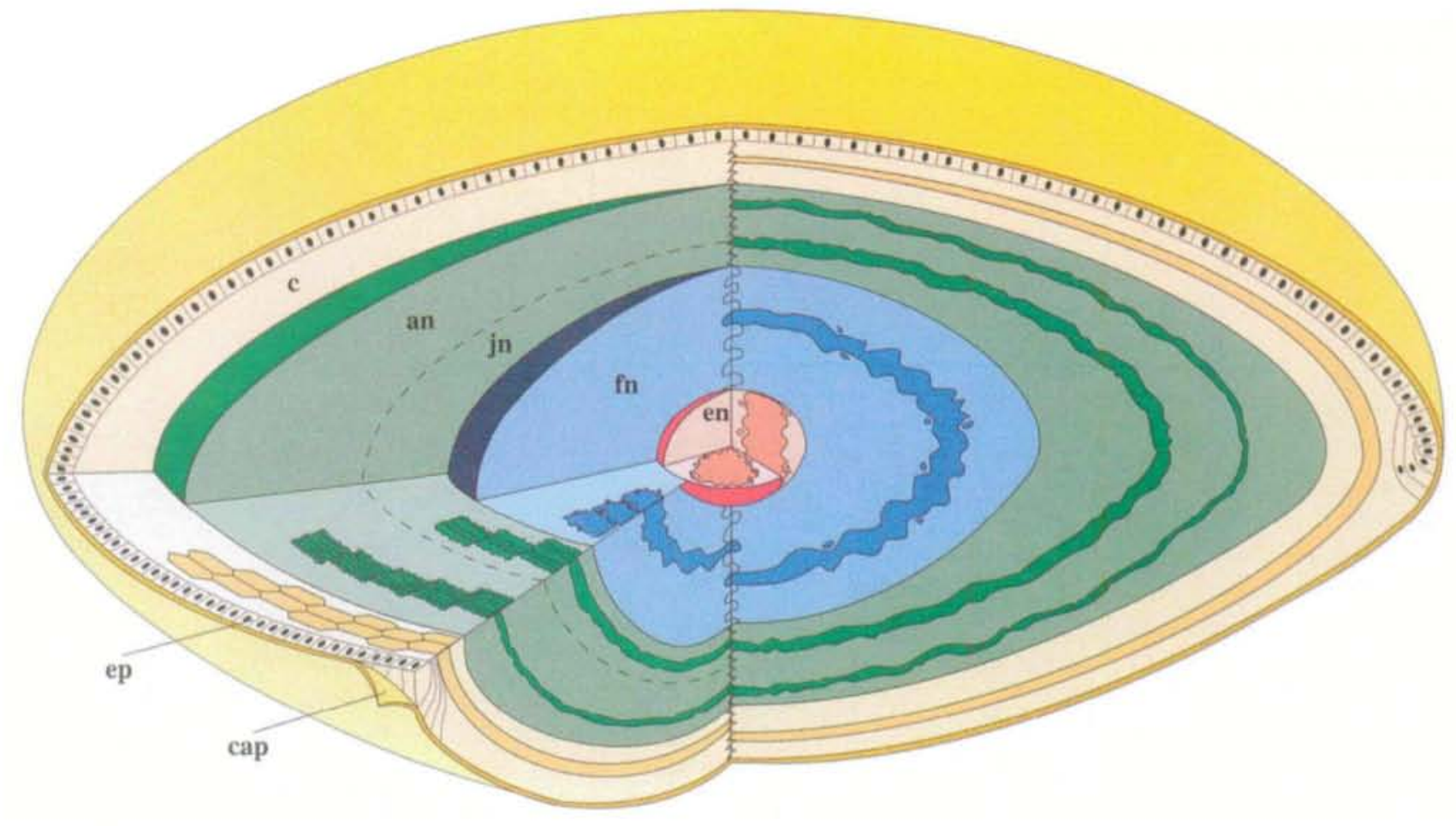

FIGURE 6. Diagram of an aged normal human lens. Fiber cell regions are approximately to scale; the embryonic nucleus is enlarged $\times 4$ to show detail. Fiber cells are approximately to scale in relation to each other but not with respect to the lens regions. Cross-sections are shown on the left, longitudinal sections on the right. The complex suture pattern is not shown. The epithelium (ep) and capsule (cap) are enlarged for clarity. $c=$ cortex; an = adult nucleus; $j n$ = juvenile nucleus; $f \mathbf{n}=$ fetal nucleus; $e n=$ embryonic nucleus. 
TABLE 2. Approximate Number of Cells in Each Region of the Lens and the Average Regional Growth Rate per Year*

\begin{tabular}{lccr}
\hline & Cell Size $(\boldsymbol{\mu m})$ & Number of Cells & $\begin{array}{c}\text { Growth Rate } \\
\text { (cells/year) }\end{array}$ \\
\hline Cortex & $2.24 \times 14 \ddagger$ & 665,000 & 133,000 \\
Adult nucleus & $0.75 \times 7.5 \ddagger$ & $4,460,000$ & 101,000 \\
Juvenile nucleus & $1.7 \times 9 \ddagger$ & 640,000 & 53,000 \\
Fetal nucleus & $5.0 \S$ & 700,000 & $1,360,000$ \\
Embryonic nucleus & $10.0 \S$ & 800 & 3500 \\
\hline
\end{tabular}

* All calculations were made on cells in the equatorial plane.

† The number of years for each region was determined using the developmental time periods defined previously, applied to a 61-year-old lens; 5 years was estimated for the cortex and puberty was assumed to occur at age 12 .

$\ddagger$ Thickness $\times$ width for an average cell.

$\S$ Diameter of equivalent circular cell with measured average area.

plexity of undulating membrane pairs and fiber age was documented previously by Dickson and Crock, ${ }^{14}$ Kuwabara, ${ }^{15}$ and Kuszak et al $^{16}$ for primates and by Kuszak et $\mathrm{al}^{23,47}$ for humans. High-amplitude undulating membranes have been observed as well in condensed and degenerated cells. ${ }^{21,24,29,48}$ It seems probable that undulating membranes form as a result of excess membrane that no longer has the capacity to remodel. In normal fiber cells, this would occur during compaction as water is lost and cell volume decreases. ${ }^{49}$

\section{Cellular Morphometry}

Many of the observed structural characteristics of nuclear fiber cells, such as shape and cellular arrangement, were apparent by SEM, although the use of cross-sections viewed by TEM in properly fixed tissue has revealed new quantitative information that had not been previously available. The most significant examples are the difference in cell area and arrangement in each region. Previously, it was proposed that the regular spacing of fibers of a constant size was necessary for transparency.' However, other investigators speculated that fiber cells were not uniform in all regions of the lens, ${ }^{11,13,15,50}$ and Rae et $\mathrm{al}^{3}$ demonstrated this in the frog lens. Our images from the fetal and embryonic nuclei of normal human lenses clearly indicate that a crystalline arrangement of uniform fibers is not required for transparency. Both SEM and TEM were essential for obtaining a realistic view of the complex geometry of fiber cells.

Correlating TEM and SEM micrographs of normal human lenses has also made it possible to identify many different characteristics of differentiated fiber cells. It has been observed that fiber cells of a particular region have unique features that distinguish them from cells of other regions. With this new descriptive information, it is now possible to determine to which region a fiber cell belongs by studying the characteristics of the cell (see Fig. 6).
Furthermore, based on the morphometry, we have made rough estimates of the number of cells and the growth rates in each region (Table 2). The fetal nucleus contains approximately $700 \times 10^{3}$ cells but is formed at a rate of approximately $1.4 \times 10^{6}$ cells/ year. In contrast, the adult nucleus contains approximately $4.5 \times 10^{6}$ cells and grows only at approximately $100 \times 10^{3}$ cells/year. These large differences between regions reinforce the distinctive morphologic features of their characteristic fiber cells. It should be emphasized that the growth rates are rough estimates, specifically those of the outer lens regions. The length of time for cortical differentiation is unknown, and the onset of puberty varies among individuals. In addition, the cells of the adult region are compacted extensively in the aged lens, resulting in an elevated value for the number of cells per unit length. This parameter does not accurately reflect the appearance of the adult nucleus in a young lens. Based on the commonly held view that the lens growth rate decreases with age, we would expect that the growth rates for the cortical and adult nuclei would be less than for the juvenile nucleus. The fact that the opposite is observed may be explained in part by the possible sources of error stated above. Nevertheless, the rough estimates emphasize the distinct difference in rates of fiber cell deposition before and after birth and establish a foundation for refinement when more detailed information becomes available.

Thin-section images showed that cytoplasm texture was smooth and staining was uniform throughout entire cells and among adjacent cells in all regions studied. These observations are consistent with the idea that the cell contents are composed of randomly close-packed crystallins in the form of a partially dehydrated gel. The hardness of the nuclear material of all aged normal human lenses examined, together with the absence of significant cytoskeletal components and the low membrane:cytoplasm ratio in the fetal and embryonic nuclei, suggests further that the 
crystallins within the gel are cross-linked into a threedimensional network. Many laboratories have provided strong evidence for covalent cross-linking of crystallins, primarily through oxidative reactions, which produces high molecular weight species that increase with age even in normal lenses. ${ }^{45,51}$ The homogeneity of the packing of proteins is emphasized further by our images of thin sections that are typically 60-nm thick, which is much less than the average size of objects $(>200 \mathrm{~nm}$ ) needed to produce significant light scattering. ${ }^{52}$ The absence of observable spatial fluctuations of staining density within thin sections is strong support for a cytoplasmic network composed of proteins packed closely enough to minimize particle scatter by white light.

\section{Key Words}

electron microscopy, fiber cells, image analysis, lens senescence, lens ultrastructure

\section{Acknowledgments}

The authors thank Dr. Craig Fowler (Duke University Eye Center) and Mr. William Woodard at the North Carolina Eye and Human Tissue Bank (Durham, NC) for supplying normal human lenses.

\section{References}

1. Trokel S. The physical basis for transparency of the crystalline lens. Invest Ophthalmol. 1962;1:493-501.

2. Rabl C. Über den Bau und die Entwicklung der Linse. Ztschr F Wissensch Zool. 1900;67:1-138.

3. Rae JL, Truitt KD, Kuszak JR. The use of procion dyes for light microscopy of the frog lens. Invest Ophthalmol Vis Sci. 1983;24:1167-1171.

4. Costello MJ, Oliver TN. Fiber cell architecture in the nuclei of bovine and senescent human lenses. ARVO Abstracts. Invest Ophthalmol Vis Sci. 1992;33:1170.

5. Al-Ghoul KJ, Lane CW, Costello MJ. Fiber cell shape and cytoplasmic texture in human lens nuclei. Curr Eye Res. 1996; in press.

6. Taylor VL, Al-Ghoul KJ, Lane CW, Davis VA, Kuszak JR, Costello MJ. Morphology of the normal human lens. ARVO Abstracts. Invest Ophthalmol Vis Sci. 1995; 36:S261

7. Delaye M, Tardieu A. Short range order of crystallin proteins accounts for eye lens transparency. Nature. 1983;302:415-417.

8. Wanko T, Gavin N. Electron microscope study of lens fibers. J Biophys Biochem Cytol. 1959;6:97-102.

9. Cohen AI. The electron microscopy of the normal human lens. Invest Ophthalmol. 1965;4:433-446.

10. Hansson HA. Scanning electron microscopy of the lens of the adult rat. $Z$ Zellforsch. 1970;107:187-198.

11. Farnsworth SC, Fu SCJ, Burke PA, Bahia I. Ultrastructure of rat eye lens fibers. Invest Ophthalmol. 1974; 13:274-279.

12. Harding CV, Susan S, Murphy H. Scanning electron microscopy of the adult rabbit lens. Ophthalmic Res. 1976; 8:443-455.

13. Hoyer HE. Scanning electron-microscopic study of lens fibers of the pig. Cell Tissue Res. 1982;224:225232.

14. Dickson DH, Crock GW. Fine structure of primate lens fibers. In: Bellows JG, ed. Cataract and Abnormalities of the Lens. New York: Grune \& Stratton Inc; 1975:49-59.

15. Kuwabara T. The maturation of the lens cell: A morphologic study. Exp Eye Res. 1975;20:427-443.

16. Kuszak JR, Ennesser CA, Umlas J, Macsai-Kaplan MS, Weinstein RS. The ultrastructure of fiber cells in primate lenses: A model for studying membrane senescence. J Ultrastruct Mol Struct Res. 1988;100:60-74.

17. Willekens B, Vrensen $G$. The three-dimensional organization of lens fibers in the rhesus monkey. Craefe's Arch Clin Exp Ophthalmol. 1982;219:112-120.

18. Hogan MJ, Alvarado JA, Weddell JE. Lens. In: Histology of the Human Eye. Toronto: WB Saunders; 1971:638677.

19. Matsuto T. Scanning electron microscopic studies on the normal and senile cataractous human lenses. Acta Soc Ophthalmol Jpn. 1973;77:155-174.

20. Tripathi RC, Tripathi BJ. Lens morphology, aging, and cataract. $J$ Gerontol. 1983;38:258-270.

21. Kobayashi $Y$, Suzuki $T$. The aging lens: Ultrastructural changes in cataract. In: Bellows JG, ed. Cataract and Abnormalities of the Lens. New York: Grune \& Stratton; 1975:313-343.

22. Vrensen G, Kappelhof J, Willekens B. Morphology of the aging human lens. Lens Eye Tox Res. 1990; 7:1-30.

23. Kuszak JR, Deutsch TA, Brown HG. Anatomy of aged and senile cataractous lenses. In: Albert D, Jakobiec F, eds. Principles and Practices of Ophthalmology. Philadelphia: WB Saunders; 1992:564-574.

24. Costello MJ, Oliver TN, Cobo LM. Cellular architecture in age-related human nuclear cataracts. Invest Ophthalmol Vis Sci. 1992;33:3209-3227.

25. Kuszak JR. The development of lens sutures. Prog Retinal Eye Res. 1995; 14:567-591.

26. Duke-Elder S, Cook C. System of Ophthalmology. Vol. III. Normal and Abnormal Development. St. Louis: CV Mosby; 1963:309-324.

27. Berliner ML. Biomicroscopy of the Eye: Slit Lamp Microscopy of the Living Eye. New York: Paul B Hoeber; 1949:948-1019.

28. Slamovits, TL. Basic and Clinical Science Course Section 11: Lens and Cataract. San Francisco: American Academy of Ophthalmology; 1995:27-30.

29. Al-Ghoul KJ, Costello MJ. Morphological changes in human nuclear cataracts of late-onset diabetics. Exp Eye Res. 1993;57:469-486.

30. Kuszak JR, Ennesser CA, Bertram BA, ImherrMcMannis S, Jones-Rufer LS, Weinstein RS. The contribution of cell-to-cell fusion to the ordered structure of the crystalline lens. Lens Eye Tox Res. 1989;6:639_ 673.

31. Rasband W. Image Version 1.21, User's Guide PB90123308. Bethesda: National Institutes of Health; 1989.

32. Remington RD, Schork MA. Statistics With Applications to the Biological and Health Sciences. 2nd ed. Englewood Cliffs: Prentice-Hall; 1985:313-316.

33. Dickson DH, Crock GW. Interlocking patterns on primate lens fibers. Invest Ophthalmol: 1972;11:809-815. 
34. Kuszak J, Alcala J, Maisel H. The surface morphology of embryonic and adult chick lens fiber cells. $A m J$ Anat. 1980;159:395-410.

35. Vrensen G, Marle J, Veen H, Willekens B. Membrane architecture as a function of lens fibre maturation: A freeze fracture and scanning electron microscopic study in the human lens. Exp Eye Res. 1992;54:433446.

36. Phelps Brown NA. The lens. In: Spalton DJ, Hitchings RA, Hunter PA, eds. Allas of Clinical Ophthalmology. 2nd ed. London: Wolfe; 1994:11.2-11.26.

37. Fine H. Cortical cleaving hydrodissection. J Cataract Refract Surg. 1992;18:508-512.

38. Garland DL, Duglas-Tabor Y, Datiles MB, Zigler JS, Magno B. Analysis of human lens proteins during fiber cell maturation. ARVO Abstracts. Invest Ophthalmol Vis Sci. 1995;36:S822.

39. Kuszak JR, Bertram BA, Rae JL. The ordered structure of the crystalline lens. In: Hilfer SR, Shaffield JB, eds. Development of Order in the Visual System. New York: Springer-Verlag; 1986:35-60.

40. Pierscionek BK, Augusteyn RC. Growth related changes to functional parameters in the bovine lens. Biochim Biophys Acta. 1992;1116:283-290.

41. Tardieu A, Vérétout F, Krop B, Slingsby, C. Protein interactions in the calf eye lens: Interactions between beta-crystallins are repulsive whereas in gamma-crystallins they are attractive. Eur Biophys J. 1992;21:1-12.

42. Kenworthy AK, Magid AD, Oliver TN, McIntosh TJ. Colloid osmotic pressure of steer alpha and beta crystallins: Possible functional roles for lens crystallin distribution and structural diversity. Exp Eye Res. 1994;59:11-30.
43. Kuszak JR, Macsai MS, Bloom KJ, Rae JL, Weinstein RS. Cell-to-cell fusion of lens fiber cells in situ: Correlative light, scanning electron microscopic, and freezefracture studies. J Ultrastruct Res. 1985;93:144-160.

44. Hoenders $\mathrm{HJ}$, Bloemendal $\mathrm{H}$. Lens proteins and aging. J Gerontol. 1983;38:278-286.

45. Zigler JS. Lens proteins. In: Albert D, Jakobiec F, eds. Principles and Practices of Ophthalmology. Philadelphia: WB Saunders; 1994:97-113.

46. Thomson JA, Augusteyn RC. Ontogeny of human lens crystallins. Exp Eye Res. 1985; 40:393-410.

47. Kuszak JR, Brown HG. Embryology and anatomy of the crystalline lens. In: Albert D, Jakobiec F, eds. Principles and Practices of Ophthalmology. Philadelphia: WB Saunders; 1994:82-96.

48. Dilley KJ, Bron AJ, Habgood JO. Anterior polar and posterior subcapsular cataract in a patient with retinitis pigmentosa: A light-microscopic and ultrastructural study. Exp Eye Res. 1976;22:155-167.

49. Fine BS, Yanoff M. The lens. In: Ocular Histology: $A$ Text and Atlas. 2nd ed. New York: Harper \& Row; 1979:147-159.

50. Kuszak JR, Macsai MS, Rae JL. Stereo scanning electron microscopy of the crystalline lens. Scanning Electron Microsc. 1983;3:1415-1426.

51. Jedziniak JA, Kinoshita JH, Yates EM, Hocker LO, Benedek GB. On the presence and mechanism of formation of heavy molecular weight aggregates in human normal and cataractous lenses. Exp Eye Res. 1973;15:185-192.

52. Benedek GB. Theory of transparency of the eye. Appl Opt. 1971; 10:459-473. 